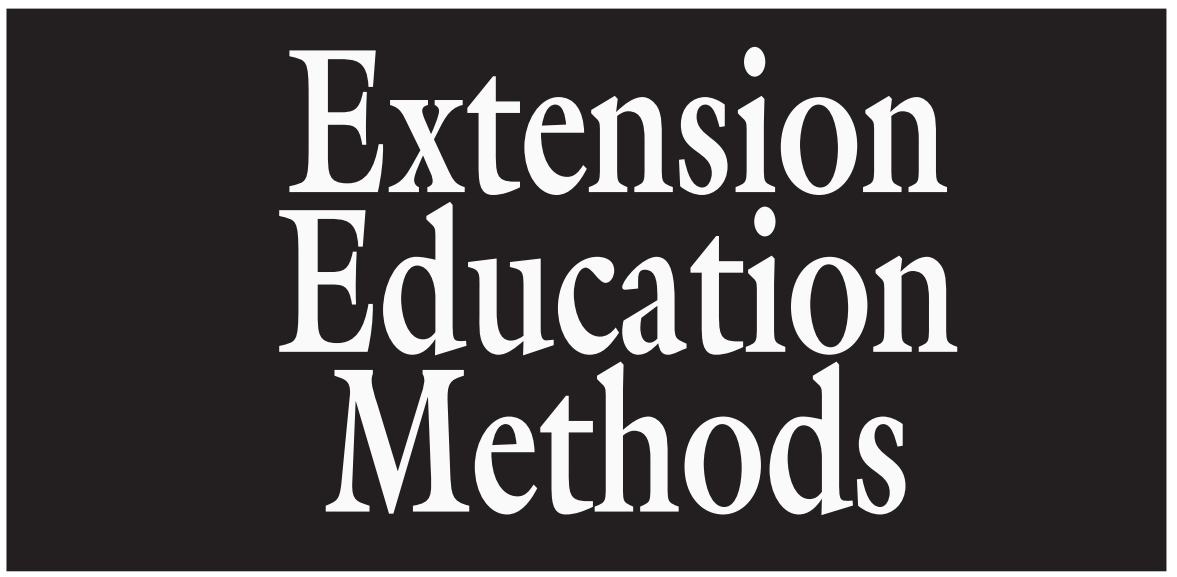

\section{Securing the Food Chain: The 2000-04 Southeastern U.S. Fresh Produce Food Safety Train-the-Trainer Program}

\author{
Dennis J. Osborne ${ }^{1}$, Douglas C. Sanders ${ }^{1}$, Donn R. Ward ${ }^{2}$, and \\ James W. Rushing ${ }^{3}$
}

AdDITIONAL INDEX WORDS. GAPs, train-the-trainer, third party audit, farm-totable, homeland security, risk management, Hispanic training

Summary. Between 2000 and 2004, a 12-state consortium in the southeastern United States used a "train-the-trainer" effort to introduce good agricultural practices (GAPs) to the region's fresh produce growers, packers, and consumers. Supported by the National Food Safety Initiative, the consortium created and implemented training by using a program and supporting materials specifically applicable to conditions and commodities in southern states. Because several factors distinguish the southeastern U.S. fresh produce industry from that of other regions in the U.S., a region-specific training program addressing distinguishing factors was needed. Distinguishing factors include: 1) southeastern U.S. producers are typically grower-packers, with some notable exceptions in Florida and Texas; 2) most such producer entities are seasonal, have their own packinghouse operation, are small-scale in that they pick what they grow and pack and often use migrant and seasonal labor; 3 ) modern worker training, sanitary practice, and facilities and supervisory expertise are either somewhat limited or completely lacking; and 4) the use of seasonal and migrant labor dictates the use of Spanish language interpreters and training. To meet fresh produce food safety training needs for the region, project leaders created a 329-page training program and associated PowerPoint presentation-containing compact disc, nine four-page crop-specific brochures relating GAPs to crop "groups," a Spanish language handwashing video and a new model recall program for the fresh produce industry. The leveraging effect of this train-the-trainer effort ultimately reached nearly 20,000 people in this multi-disciplinary, multi-state, integrated project, thus expanding and reinforcing regional cooperative extension efforts.

$\mathrm{T}$ his article summarizes the results of a multi-state, multi-institutional partnership delivering a targeted "train-the-trainer" program. The program provided GAPs and good manufacturing practices (GMPs)based training to southeastern U.S. fresh fruit and vegetable (produce) growers and packers. Twelve southern U.S. states cooperated in this project:
Arkansas, Florida, Georgia, Kentucky, Louisiana, Mississippi, North Carolina, Oklahoma, South Carolina, Tennessee, Texas, and Virginia. The 2000-04 work was funded by U.S. Department of Agriculture, Cooperative State Research, Education, and Extension Service (USDA-CSREES) National Food Safety Initiative grants. Although proposed long before events of 11 Sept. 2001 , the project involved new food security procedures that became even more relevant following those events. Consumer expectations regarding the nation's food supply incorporated a new security consciousness and accepted risk management considerations and training addressed in this project.

Problem statement. Consumers have long trusted that food handlers (including producers, processors, and preparers) used procedures ensuring that food products came to the consumer clean, safe, and ready to eat. While such trust is still the rule, both terrorist activity and foodborne disease outbreaks have made consumers less willing to rely on faith alone as assurance of food quality. Many people today probably wonder: "How DO I know THIS is safe to eat?"

Indeed, critical inquiry is warranted. As with meat and poultry, fresh produce is subject to bacterial contamination from Listeria, Salmonella, and other microorganisms (Olsen et al., 2000). Contamination can come from many places: bird droppings falling into harvest bins, bacterially contaminated water, farm workers touching produce with unwashed hands, and so on. Recently both the public and public interest groups are realizing that people "get sick" from contaminated produce as well as from tainted meat. For instance, a study by the Center for Science in the Public Interest (CSPI) (DeWaal and Barlow, 2002) found 10,504 cases of food poisoning from produce between 1990 and 2001, compared with 6089 for meat and 4279 for poultry. The contamination problem is persistent and worldwide. As an example, as of Oct. 2002 most cantaloupe melons (Cucumis melo) from Mexico were embargoed from

${ }^{1}$ Department of Horticultural Science and ${ }^{2}$ Department of Food Science, North Carolina State University, Raleigh, NC 27695-7609.

${ }^{3}$ Clemson University Coastal Research and Education Center, Charleston, SC 29414-5333.

Acknowledgments. This project was sponsored by USDA-CSREES Project Number 00-51110-9722 of the National Integrated Food Safety Initiative. Any of its successes are due to the cooperative efforts of people representing each land grant institution food science and horticultural science department in the 12 southeastern U.S. states, whose work is hereby acknowledged. Those people include: Jeffrey K. Brecht, Michael Mahovic, Steven A. Sargent, Mark A. Ritenour, Keith R. Schneider, Amy Simonne, Jerry Bartz, William C. Hurst, Darbie Granberry, Herman Hohlt, Al B. Wagner, Jr., Jimmy Boudreaux, Mike Boyette, Lynn Brandenberger, Frank Dainello, Luke Howard, Elizabeth Hoyle, Dave Lockwood, Dean McCraw, William McGlynn, William C. Morris, Brent Rowell, Juan Silva, Allen Straw, Keith Streigler, Darrell E. Blackwelder, Diane Ducharme, Tom Dyson, Bill Hanlin, Bill Jester, Billy Little, Allan Thornton, Wick Wickliffe, and Taylor Williams. 
U.S. entry due to outbreaks of illness associated with their consumption.

Reported fresh produce-related foodborne illness cases doubled between the 1973-87 and 1988-92 reporting periods (Tauxe et al., 1997) and increased again in 1995 (National Advisory Committee on Microbiologic Criteria for Foods, 1998). Demonstrating the potential spread of producerelated problems, 1991 and 1993 outbreaks of salmonellosis (caused by Salmonella enterica) in the midwestern U.S. were linked to the handling of raw tomatoes (Lycopersicon esculentum) occurring in a single packinghouse in South Carolina (Rushing, 2001).

That this particular outbreak originated in a southern U.S. operation is not surprising. First, significant amounts of U.S.- grown fresh produce are raised in southeastern states. Second, seasonal labor harvests much of those crops. Third, southern states' fresh produce growers have only recently been viewed as "food handlers" and have rarely been included in food safety educational programs. Last, both the total amount of fresh produce being consumed and the proportion of the consuming population at risk for foodborne disease are increasing.

ADDRESSING THE PROBLEM: BACKGROUND. Engaging southern U.S. growers and packers in a new national food safety dialogue should increase food security, food safety, and the awareness of producers and consumers alike. No one knows how many "growers" are in the fresh produce system. Cooperating state departments of agriculture estimated there were thousands of such producers in each state. There are so many growers we judged that a "multiplier" educational program was essential to reach a reasonable number of the growers. Because few, if any educational materials addressing the problem existed, the materials would have to be created. While outreach and extension programs had long been addressed to farm populations, no such programs specifically delivering educational programming about fresh produce food safety, GAPs, and food security concerns had been developed. This project developed materials, pilot tested them, refined them for use by a regional group of specialized agents, assisted the agents in delivering the new programming, and evaluated the results.

Addressing the Problem: Pro-
GRAM CHOICE AND DELIVERY METHOD. Extrapolating GAPs concepts to the nation's broader food safety problems involved an integrated effort involving crop production systems, crop handling, and crop marketing systems. Most southeastern U.S. producers are small entities. This situation suggested that new training initiatives had to be farm- and packingline-specific. The climate and growing systems across the region are similar, suggesting a regional approach could be effective for program planning. Many kinds of produce identified in reported outbreaks are typical of those grown in the southeastern U.S., such as leafy greens [e.g., collard greens (Brassica oleracea var. acephala)], onions (Allium cepa), carrots (Daucuscarota), celery (Apium graveolens), melons [e.g., watermelon (Citrullus lanatus)], berries [e.g., blackberry (Rubus spp.)], and tomatoes. A recent literature review (Institute of Food Technologists, 2001) considered the reduction/elimination of microbial hazards and noted that most existing work was in laboratories, whereas new applied, in-the-packinghouse research efforts were needed to increase food safety in the operations of southern states.

For these reasons a "train-thetrainer" technique was the program delivery method chosen. Training materials were designed for the training agents who interacted with seasonal packing houses and grower/packer entities. The training agents were selected from the region's experienced horticultural and vegetable crops extension agents. In each state the training agents were selected to represent a production area within a state; each state's major crops were "covered"; nearly all fresh produce areas in the southeastern U.S. were thus involved.

The term "train-the-trainer" is often used but seldom defined. In this project "train-the-trainer" meant providing specialized information and educational programming to a selected cohort of people noted for their ability to effectively deliver extension programs based on that specialized information. The trainers in the cohort become area-specialized information resources supporting those whom they have trained in extension programs, and the trainees later become trainers in local townships and rural areas. Trainthe-trainer is thus a training system creating a multiplier approach following the adage of "each one teach another." Because an initial cohort often reaches first adopters and because later adopters often follow practices of first adopters, the leveraging of resources in such a system can be logarithmic rather than geometric.

AdDRESSING THE PROBLEM: CURRICULUM DEVELOPMENT. Any training entity needs a curriculum. No food safety curriculum for the southern U.S. producer existed. This meant that before training trainers, but preferably in partnership with them, a curriculum would be developed for them to use. In this project the initial cohort functioned very effectively as partners in curriculum development because cohort members were intimately familiar with production practices and farms in their locale. Cohort members were thus able to offer producer-relevant suggestions and cite personal success stories in applying training methods.

The regional partnership was guided by national policy at the time the initial curriculum was being planned. By 1997 reported outbreaks of microbial based foodborne illness provided impetus for a federal "Initiative to Ensure the Safety of Imported and Domestic Fruits and Vegetables" (Initiative). A philosophical and practical framework for the Initiative was provided by the U.S. Food and Drug Administration (FDA). For the fresh produce industry FDA released the Guide to Minimize Microbial Food Safety Hazards for Fresh Fruits and Vegetables [Guide (FDA, 1998a)]. The Guide defined GAPs and showed interested parties how they could identify potential fresh produce contamination sources. Further, the Guide suggested that using GAPs could reduce or eliminate potential contamination. Conceptually the Guide can be viewed as a programmatic relative of Hazard Analysis Critical Control Points (HACCP) for minimal process operations. The FDA had published guidance for such industries in the Federal Register (FDA, 1998b) and while apparently looking toward an integrated national food safety framework, FDA realized users would have to fill in details implementing the framework.

As a policy document, the Guide offers broad statements and users must fill in details. For a regional effort, specific procedures implementing each GAP and specific GAPs guidelines for each commodity had to be created and introduced to the southern fresh 
produce industry.

Developing a GAPs-based curriculum became a two-fold process: drafting and piloting materials in initial cohort exercises in four regional meetings, then creating and introducing southern U.S. crop-specific and industry guidelines via regional publications such as Fresh Produce Food Safety Training Program for the Southeast (Osborne et al., 2001) and Good Agricultural Practices for the Production and Handling of ... (nine publications, one for each major southeastern U.S. fruit or vegetable group) (Sanders et al., 2002).

Implementing any one specific GAP (Practice) would require that each adopter create specific strategies around that Practice. We called that process a GAPs analysis. The analysis is analogous to the systems thinking of HACCP and HACCP-like programs. GAPs differs from HACCP in that fresh produce operations may have fewer critical control points, and corrective actions may be less costly than is the case in process operations. Also, critical production "activity areas" such as planting, harvest, and packing occur in crop production and any or all of the GAPs may apply to one activity area.

ADDRESSING THE PROBLEM: Specific. Regional buyers develop and apply national market standards. Such standards are de facto regional standards. National application of regional standards means that food safety aspects of the southeastern U.S. fresh produce industry could be addressed on a local producer scale, while market development could be addressed on either the regional or national scale. The ultimate effect of such an approach became a national impact. This is because microbiologically "safe" southeastern U.S. produce moves to market throughout the country, validating consumer trust reposed in the industry. Validating consumer trust in the existing food supply system and assuring safe fresh produce thus became overarching goals.

Addressing the problem: DIRECTED GOAL SET. Achieving these overarching goals was facilitated by the following goal set that directed curriculum development, training, and assessment methods:

A. Improve the safety of fresh and minimally processed fruits and vegetables by implementing GAPs principles and utilizing currently available educational materials applicable to the southeastern U.S.

B. Produce new and/or supplemental training material for southeastern U.S. fresh produce growers and packers.

C. Provide comprehensive training to trainers (cooperative extension agents and major growers) on the application and implementation of GAPs and standards delineated in the Guide and applicable to the southeastern states' situation. These trainers would in turn conduct similar training for other home state agents and fresh produce handlers.

D. Develop materials and presentations sending a consistent fresh produce food safety message to commodity groups and fresh produce handlers. Commodity meetings served to introduce the concept of GAPs to fresh produce industry leaders and bring to their attention the concern for food safety held by corporate buyers and local consumers. Assist growers implementing internal checks and GAPs documentation for various groups of fresh produce, including stone fruit (Prunusspp.), citrus (Citrus spp.), berries, fruiting vegetables [e.g., sweet pepper (Capsicum annuиm)], leafy vegetables [e.g., lettuce (Lactuca sativa)], green beans (Phaseolus vulgaris), and root vegetables [e.g., radish (Raphanussativus)]. Conduct training in the Spanish language as needed.

E. Assist growers and packers in providing information for supplier guarantees and/or warranties for food safety certification programs.

F. Collaborate with regulatory authorities on appropriate and acceptable recordkeeping methods and checklists and transfer this information to fresh fruit and vegetable handlers on a crop-specific basis.

G. Present the progress toward implementation results of the work at appropriate county, state, national, or international annual meetings.

\section{Results}

After an initial National Science and Education Conference meeting in 1999, fresh produce food safety awareness increased within the southern U.S. For example, in South Carolina a multi-disciplinary interagency committee formed to foster a new government-industry-university partnership to develop a comprehensive training network. The committee includes regulatory agencies, industry buyers, Farm
Bureau, and university departments of food science, toxicology, horticulture, and agricultural engineering. Roundtable discussions involving cooperative extension specialists and grocery chains produced consensus about the needs for 1 ) a practical guide to reduce risk of foodborne microbial disease, 2) production of standardized training materials, and 3) specific kinds of producer/packer-oriented programs.

As noted before in this article, a train-the-trainer program delivery model was developed for this project. Figure 1 shows data that validate the efficacy of such a training scheme in the context of this project. First, the more trainers trained per session at a first "round" of training, the higher was the total number of people finally trained. This is because each "first rounder" led later training sessions attended by colleagues and client/ growers, and each of these "second rounders" likewise led training sessions for succeeding "generations" of colleagues and client/growers. The ratios of client/growers reached by project end to trainers in first "rounds" show a marked leveraging effect. Seven first round sessions were eventually held and final outreach contacts showed ratios ranging from 10:1 to 133:1, where the work of 15 "first rounders" eventually reached 2000 people. In operation, a train-the-trainer system is thus seen to work somewhat as do pyramid sales systems: a few people in a first group reach many more people in a second group, each of whom then reach many more in a third group, etc.

While relatively few attendees (only five or 10 per session) were in some states' first trainee groups, over the project life each of those few attendees later trained 10 or more cooperative extension clients. We call one person training many a "leveraging effect" of having trained the first group. In this project the first group trained a second, and that second training program's leveraging effect produced between 50 and 150 more trained people. Third round and later trainings in each state attracted ever more attendees and the leveraging effect obtained from the outreach of second and succeeding generations created large total numbers of people reached over project life. Actual numbers of people reached was nearly 20,000 , a number arrived at by counting signed-in registrations for events. The exact number of southern 


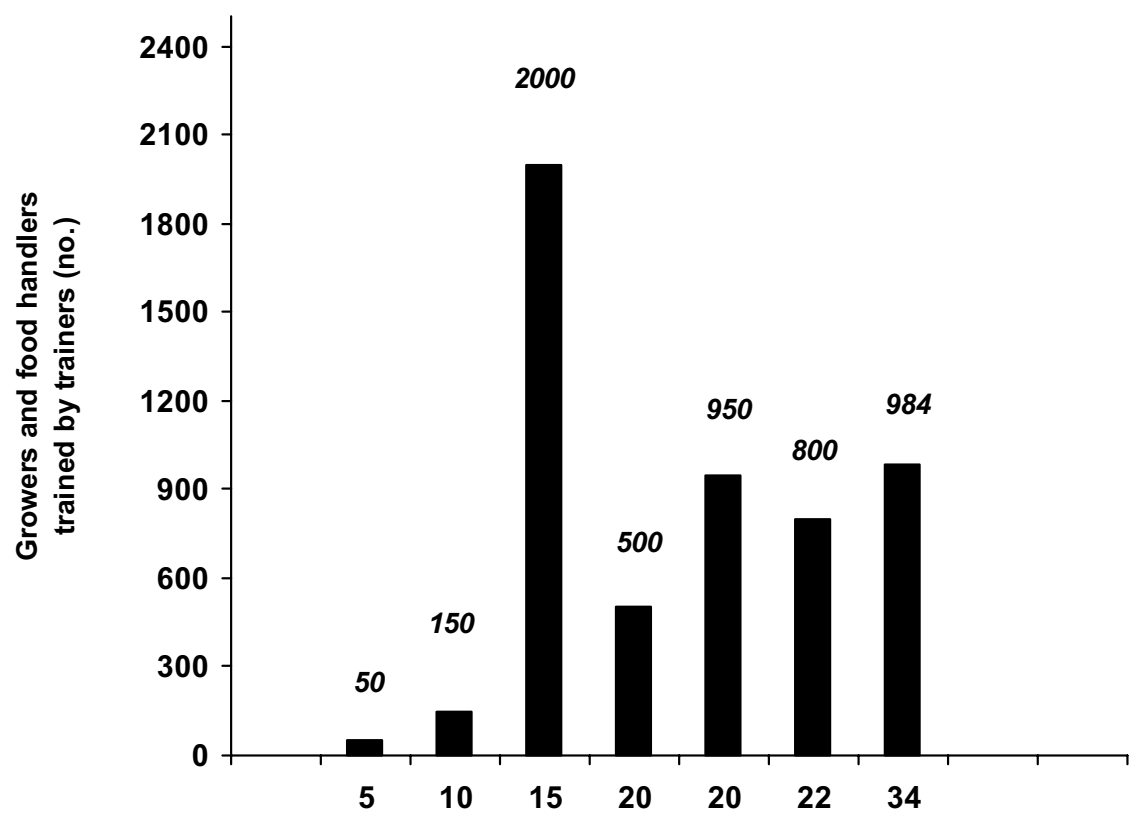

Trainers taught in one session (no.)

Fig. 1. Leveraging effect of train-the-trainer activity. Growers and food handlers instructed in seven initial "rounds" leveraged that training effort by reaching between 10 and 133 other persons in second training rounds. These "second rounders" reached more than 20,000 persons in third and subsequent training programs.

U.S. grower/clients now knowledgable concerning GAPs is unknown. However, across the southern U.S. GAPs knowledge is now commonplace and GAPs utilization is considered useful as a marketing tool.

Initial cost to train was about $\$ 6.00$ per person, including travel expense of attendees. However, by project end the leveraging effect dropped the initial cost-per-person reached from $\$ 0.60$ to $\$ 0.04$ by the end of the third outreach efforts. This is a reflection of total training dollars spent with first cohort divided by the final number of people trained as a result of those initial training dollars. This return on training investment suggests that a properly designed train-the-trainer program can provide educational programming on a regional basis at remarkably low cost per person.

Results: Regional training. In 2000 and 2001 an introductory regional series of four fresh produce food safety training programs, including GAPs and general HACCP principles, was held across the region. These initial sessions allowed for inventory, refinement, and prototype testing of materials by and for cooperative extension agents working with fruit and vegetable handlers.
Pre-tests, post-tests, and program evaluations indicated: 1) agents knew nothing about GAPs upon arrival but could define and implement GAPs principles in their local program development at the end of the training session; 2) attendees understood the importance of handwashing in fresh produce food safety; and 3 ) agents had become familiar with the relation of family and consumer science programming as it applied to fruit and vegetable handling. The initial and second training rounds created a trained group of 150 fresh produce food safety agents in 12 southeastern states. A food safety network was created in southeastern U.S. land grant institutions. That network consists of at least one cooperative extension specialist in each cooperating university's food science and horticultural science departments.

Results: District training. Next, in 2001 and 2002 each agent conducted three or more meetings about fresh produce food safety in her/his home district(s). These meetings involved approximately $4 \mathrm{~h}$ of classroom training and demonstrations of equipment, such as water quality control systems and test kits needed to properly monitor the critical control points in a HACCP-like program.

Between 2001 and 2004 these 150 trainers introduced nearly 20,000 people to GAPs principles, including over 2000 Spanish-speaking workers and a similar number of limited resource/specialty crop/grower/packer/buyer audience members. Actual numbers of people reached was arrived at by counting signed-in registrations for events. In cooperation with the USDA's Risk Management Agency, a training component about risk in fresh produce operations was developed. This unit was delivered to historically underserved audiences, small farms and roadside markets, and other nontraditional audiences. This training continues today.

Results: Training manual. Materials from the regional workshops were edited to produce a training manual that trainers can use for widely disparate audiences. The manual contains 329 PowerPoint (Microsoft Corp., Redmond, Wash.) slide pages and associated notes. Originally published only in quantity for the region, this manual is now a packaged program available on compact disc (CD). Any presenter can use the $\mathrm{CD}$ and manual to conduct fresh produce food safety training, even if relatively ignorant of the subject. To do so, a program presenter merely opens and uses one of the CD's 11 PowerPoint presentations. "Instant" programs about each of the GAPs are available to agents partnering with a community to deliver food safety programming.

Results: Crop-SPeCific LeAFLETS. A publication series of nine leaflets, each one reviewing GAPs as GAPs apply to a specific crop group, was written, printed, and disseminated. Each of the nine leaflets in the series followed a standard format presenting basic food safety procedures for the crop. These leaflets are four-page publications typical of those usually found in county extension offices. They have color highlights associated with the crop: tomato is red, cabbage (Brassica oleracea var. capitata) is green, etc. Besides the previously mentioned tomato and cabbage, featured crop groups include: green beans, strawberry (Fragaria xananassa), peach (Prunus persica), and carrot.

Each state's county and area cooperative extension agents having responsibility of working with packinghouse operators received detailed 
instruction on HACCP-like program design, implementation, and verification. These agents developed their own "train-the-trainer" programs related to fresh produce food safety. Additional, later agent training focused on recordkeeping related to each component of a HACCP-like program.

\section{Conclusions}

In conjunction with USDA a new national food safety system has been created throughout the southeastern U.S. That system has several elements that grew and evolved from a regional, multi-state multi-institutional, multidisciplinary "train-the-trainer" program. Among the system elements are a grower certification arrangement whereby cooperative extension provides training using the materials from this project; industry accepts university verification of the training and certifies trained producers as "approved"; and state departments of agriculture can provide inspectors and charge for the inspections.

A "Model Recall Program for the Fresh Produce Industry" (Osborne et al., 2003) has been developed and published following the form of FDAregulated product recall procedure. A model recall program is one usable by many entities. Recall programs for food products differ from those used for manufactured products in interstate commerce. Processed food products are regulated by FDA and a federal statute explicitly states every step to follow when a producer has to recover defective products from the chain of commerce. Fresh produce is not a manufactured product and no statutory recall process exists for fresh produce. The model program referred to above is an adaptation of the statute for manufactured food products, but has special requirements as applicable to the fresh produce industry. Because GAPs certification requires a grower to have a recall plan, this one was developed so that a producer entity of almost any size could download it and use it. A parallel training program consisting of a series of PowerPoint programs explaining GAPs and "GAP's Simplified" has been created in both Spanish and English languages. Supporting this dual language curricula are certificates of completion, evaluation forms, and other support materials developed in both English and Spanish.

This new fresh produce food safety system has two major components. The first component is USDA's "GAPs Grower Certification Program" effected in late 2002. The grower certification is the end product of a USDA program operated in conjunction with the Federal State Inspection Service (FSIS). These two agencies created a third-party audit matrix used as an inspection guide for GAPs third-party audits performed by USDA/FSIS. Cooperative extension provides training for those desiring certification, and those being inspected are reviewed by inspectors from state departments of agriculture in some cases, by FSIS in others. People passing USDA audits are named on a USDA web page as "GAPs Certified," a designation increasingly demanded by buyers of fresh produce. While GAPs is a voluntary multi-institutional program creating market opportunities for growers of all scale, with this new process even the smallest-scale grower can be "USDA Certified" and use such designation as a marketing tool.

The second fresh produce food safety system component arose in the FDA. It is commonly called "FDA registration" because growers and others register their operations on an FDA website and receive a grower identification number.. In effect since 12 Dec. 2003, that registration (while perhaps not intended to be so) is a functional partner of GAPs certification for risk management. This is because concepts of recall, traceback, tort liability and due diligence are imbued in the procedures growers adopt to become GAPs certified. Once becoming certified, most then register with FDA because they see the utility of having a grower identification number. Growers adopting GAPs (the first component) and finding it helpful rather than harmful increasingly see no reason not to become FDA registered, too.

Other project programming included roadside market programs, liability concept training programs, certification programs for producers, new self-audit programs, and new partnerships within extension offices between family consumer science and agriculture/horticulture agents. Commercial fresh fruit and vegetable handlers acquired the knowledge and skills to establish effective HACCP-like programs. In a positive synergy growers protect themselves from liability while they protect the national food supply, and consumer confidence in the nation's fresh produce supply is validated.

\section{Literature cited}

DeWaal, C.S. and K. Barlow. 2002. Outbreak alert! Closing the gaps in our federal food safety network. Ctr. Sci. in the Public Interest, Washington, D.C.

Institute of Food Technologists. 2001. Analysis and evaluation of preventive control measures for the control and reduction/elimination of microbial hazards on fresh and fresh-cut produce. IFT/FDA Contract No. 223-98-2333, Task Order No. 3. Inst. Food Technol., U.S. Dept. of Health and Human Serv., U.S. Food and Drug Administration, Ctr. for Food Safety and Appl. Nutr., Washington, D.C.

National Advisory Committee on Microbiologic Criteria for Foods. 1998. Microbial safety evaluations and recommendations on fresh produce. NACMCF, Washington, D.C.

Olsen, S.J., J.C. MacKinon, J.R. Goulding, N.H. Bean, and L. Slutsker. 2000. Surveillance of foodborne disease outbreaks, United States-1993-1997. MMWR Surveillance Summary 49, SS01:1-51.

Osborne, D.J., D.C. Sanders, J. Rushing, and D.R. Ward. 2003. A model recall program for the fresh produce industry. J. Assn. Food Drug Officials 67(4):6-25.

Osborne D.J., D.C. Sanders, and D.R. Ward (eds.).2001. Program materials for southeastern fresh produce food safety training program, A training manual. USDA-CREES Project No. 00-51110-9722. Natl. Integrated Food Safety Initiative. Dept. of Hort. Sci., North Carolina State Univ., Raleigh.

Rushing, J.W. 2001. A case study of salmonellosis related to the consumption of fresh-market tomatoes and the development of a HACCP program. HortScience 36:29-32.

Sanders, D.C., M. Mahovic, J.K. Brecht, S.A Sargent, M.A Ritenour, K.R. Schneider, A. Simonne, and J. Bartz. 2002. Good agricultural practices for the production and handling of tomatoes. In: D.J. Osborne, D.C. Sanders, and D.R. Ward (eds.). Program materials for southeastern fresh produce food safety training program, A training manual. USDA-CREES Project No. 00-51110-9722. Natl. Integrated Food Safety Initiative. Dept. of Hort. Sci., North Carolina State Univ., Raleigh.

Tauxe, R., H. Kruse, C. Hedberg, M. Potter, J. Madden, and K. Wachsmuth. 1997. Microbial hazards and emergency issues associated wit $h$ produce: A preliminary report to the Natl.Advisory Committee on Microbiologic Criteria for Foods. J. Food Protection 60(11):1400-1408.

U.S. Food and Drug Administration. 1998a. Guide to minimize microbial food safety hazards for fresh fruits and vegetables. U.S. Food and Drug Administration, Food Safety Initiative Staff HFS-32, Washington, D.C.

U.S. Food and Drug Administration. 1998b. Hazard analysis and critical control point (HACCP); Procedures for the safe and sanitary processing and importing of juice. Federal Register 63(79):20449-20486. 